\title{
Congenital insensitivity to pain with anhidrosis
}

\section{A case report}

\author{
M. Herdem ${ }^{1}$, S. Polat ${ }^{2}$, S. Özbarlas ${ }^{1}$, E. Onaç ${ }^{1}$ \\ ${ }^{1}$ Department of Orthopaedics and Traumatology, Faculty of Medicine, University of Cukurova, Adana, Turkey \\ 2 Department of Histology, Faculty of Medicine, University of Çukurova, Adana, Turkey
}

Accepted: 5 February 1996

Summary. We present a five-year-old girl with congenital insensitivity to pain with anhidrosis. A skeletal radiographic survey revealed several old fractures. Application of pilocarpine showed anhidrosis and nerve biopsy revealed a significant decrease in the number of myelinated and unmyelinated nerve fibres.

Résumé. Le cas d'une fillette de cinq ans souffrant d'insensibilité à la douleur avec anhidrose est presentée. L'examen radiologique du squelette montre plusieurs anciennes fractures. Le test á la pilocarpine montre l'anhidrose et la biopsie de nerf révèle une dimunition significative du nombre des fibres nerveuses myelinisées et non-myelinisées.

\section{Introduction}

Congenital insensitivity to pain with anhidrosis is a hereditary sensory neuropathy. The primary clinical features include congenital analgesia, which leads to orthopaedic complications and self mutilation, and inability to sweat causing defective thermoregulation. Fractures and osteomyelitis can occur, Charcot joints may develop [8]. Abnormal findings on nerve biopsies have been reported $[3,5]$.

\section{Case report}

A five-year-old girl presented with a painless swelling of the right foot after a fall 3 months previously. She did not have an

Reprint requests to: M. Herdem, C. Ü. T. F Orthopedi ve Travmatoloji Ana bilim dalı, Balcalı Adana, Turkey. Fax: +90322-3386900 antalgic gait and inspection showed numerous scars on the limbs from previous injuries. The right elbow lacked 25 degrees of extension. Although sensation to pin prick was diminished, no other neurological abnormality was noted. She had sustained a fracture of the right forearm complicated by osteomyelitis three years before.

\section{Laboratory findings}

Laboratory tests and electromyelographic examination were normal. Radiographs of the right foot showed a healed fracture of the head of the first metatarsal, new bone formation at the back of the calcaneus (Fig. 1) and an old healed fracture of the right ulna. When the X-rays taken three years before were reviewed, the right radial head was seen to be destroyed with the appearances of osteomyelitis in the right ulna (Fig. 2). The Wasserman reaction was negative. Injection with $0.1 \mathrm{ml} 1 \%$ pilocarpine failed to induce perspiration. The intelligence quotient was normal. A biopsy of skin from the cruris demonstrated normal sweat glands but there was a decrease in the number of unmyelinated fibres around them.

A sural nerve biopsy showed a significant decrease in the number of unmyelinated and myelinated nerve fibres. Myelinated fibres were decreased to 3,219 per sq.mm compared with 12,310 per sq.mm in a matched control. The unmyelinated fibres were decreased to 6,817 per sq.mm, compared with 27,177 per sq.mm in a control. There was no selective decrease in the number of the fibres.

Electron microscopic examinations showed that most of the myelinated and unmyelinated fibres had a normal ultrastructure (Fig. 3), but $15 \%$ of the myelinated fibres exhibited focal degeneration of the myelin sheath.

\section{Discussion}

In 1962 Winkelmann had classified the sensory neuropathies including congenital indifference to pain, familial dysotonomia, congenital sensory neuropathy, hereditary sensory neuropathy, acquired sensory neuropathy and syringomyelia [9]. Congenital insensitivity to pain with anhidrosis is in a group of diseases termed hereditary sensory 

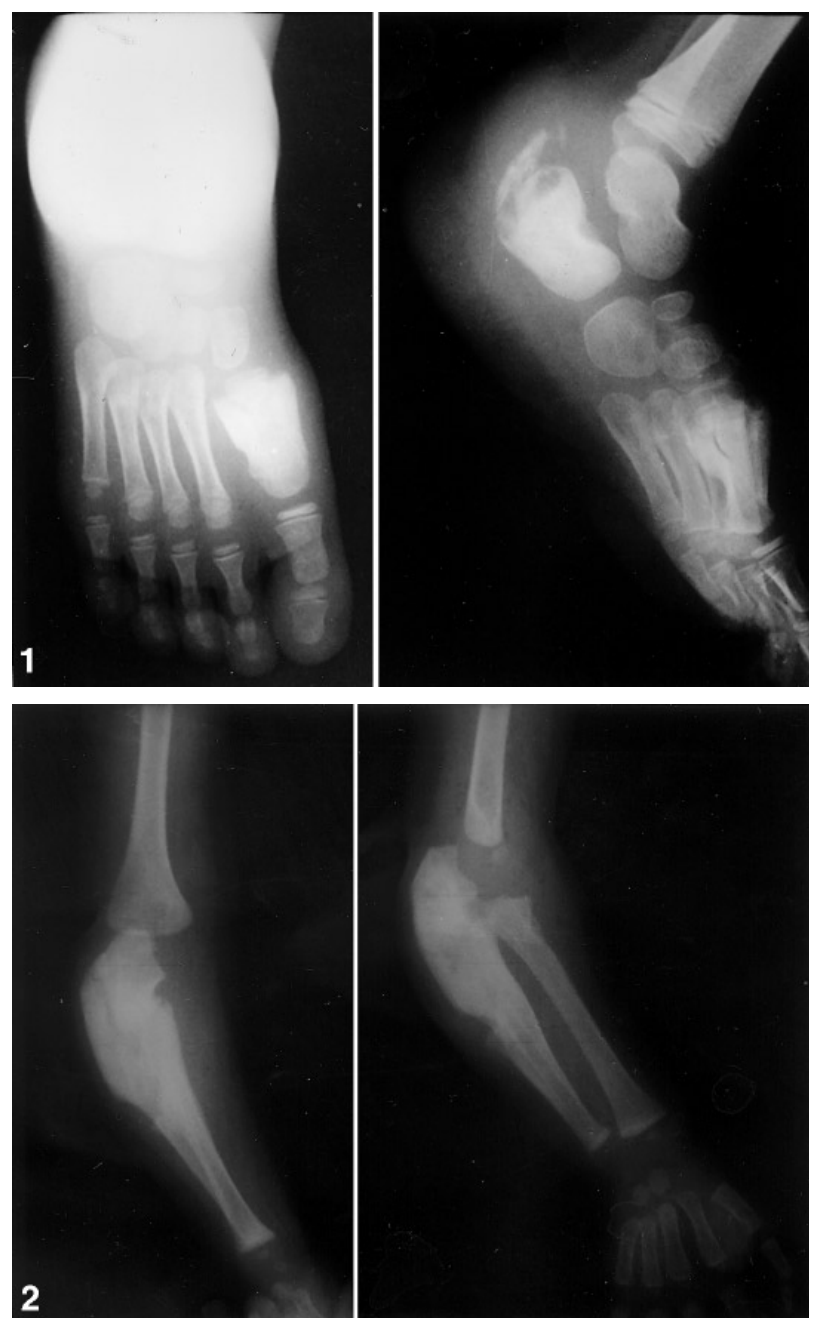

Fig. 1. Radiograph of the right foot

Fig. 2. Initial radiograph of the right ulna showing osteomyelitis

neuropathies by Dyck [1, 2]. Rafel et al. suggested that it was due to a developmental defect of the nerveous system and most patients have been mentaly retarded [7]. Okuna et al. reported that a biopsy specimen of the sural nerve revealed a marked decrease in the number of both small myelinated and unmyelinated fibres and that a skin biopsy had demonstrated an absence of unmyelinated fibres around the normal sweat glands. Eker et al. described two male siblings with congenital insensitivity to pain and showed extreme paucity of unmyelinated fibres using electron microscopic examination of the sural nerve [3]. Özbarlas et al. noted a case with congenital intensitivity to pain who had gangrenous and ulcerating lesions [6].

In our patient, biopsy of the sural nerve demonstrated a significant decrease in the number

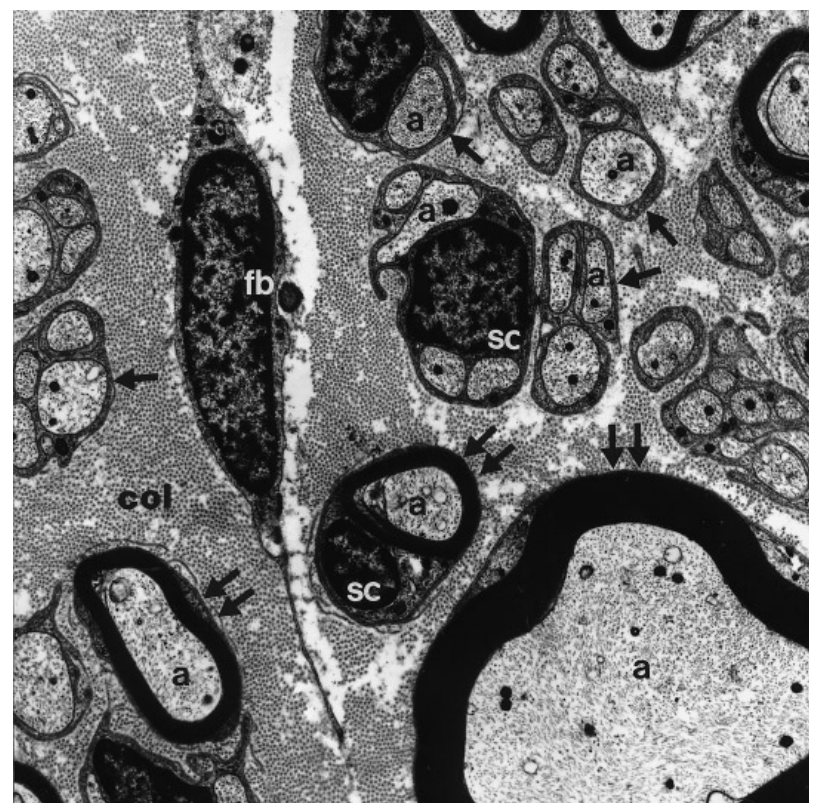

Fig. 3. The ultrastructure of the myelinated (double arrows) and unmyelinated (single arrows) nerve fibres was, in general, normal. Schwann's cell ( $s c$ ), fibroblast $(f b)$, axons $(a)$ and collagen $(\mathrm{col})$ fibres are identicated. X 8800

of the myelinated and unmyelinated fibres. The skin biopsy showed a marked decrease in unmyelinated fibres around normal sweat glands. The intelligence was normal.

\section{References}

1. Dyck PJ (1993) Neural atrophy and degeneration predominantly affecting peripheral sensory and autonomic neurons. In: Dyck PJ, Thomas PK, Lambert EH, Bunge R (eds) Peripheral neuropathy 2nd edn. Saunders, Philadelphia, pp $1065-1093$

2. Dyck PJ, Ohta M (1975) Neural Atrophy and degeneration predominantly affecting peripheral sensory and autonomic neurons. In: Dyck PJ, Thomas PK, Lambert EH (eds) Peripheral neuropathy 1st edn. Saunders Philadelphia, pp 791-812

3. Eker R, Apak MY, Erbengi T et al (1989) Congenital insensitivity to pain with anhidrosis: morphological studies of skin and peripheral nerves. Turk J Pediatr 31: 29-35

4. Millonig G (1961) Advantages of a phosphate buffer for OsO4 solutions and fixation. J Appl Physics 32: 1637

5. Okuno T, Inoue A, Izumo S (1990) Congenital insensitivity to pain with anhidrosis. J Bone Joint Surg [Am] 72: 279-282

6. Özbarlas N, Sarikayalar F, Kale G (1993) Congenital insensitivity to pain with anhidrosis. Cutis 51: 373-374

7. Rafel E, Alberca R, Bautısta J, Navarrete M, Lazo J (1980) Congenital insensitivity to pain with anhidrosis. Muscle nerve 3: $216-220$

8. Tachdj1an MO (1990) Congenital insensitivity to pain. In: Pediatric orthopedics 2nd edn. Saunders, Philadelphia, pp 1992-2000

9. Winkelmann RK, Lambert EH, Hayles AB (1962) Congenital absence of pain. Report of a case and experimental studies. Arch Dermatol 85: 334 